\title{
CJEM and the changing landscape of medical education and knowledge translation
}

\author{
Brent Thoma, MD, MA*; Rohit Mohindra, $\mathrm{MD}^{\dagger}$; Jennifer D. Artz, PhD ${ }^{\ddagger}$; Teresa M. Chan, MD, MEd
}

The papyrus leaf. The Gutenberg printing press. The Internet. What do all of these technologies have in common? They all have disrupted the way that we communicate. The adoption of technology occurs along a predictable curve. ${ }^{1}$ Innovators lead the way, taking a new concept and introducing it to the world. Next come the early adopters, often opinion leaders, who engage in new practices. Eventually, the majority develops an increasing interest in the phenomena and makes it their own. Now, communication within the emergency medicine (EM) community is being disrupted by the Free Open Access Medical (FOAM) education movement. ${ }^{2}$

A trend that started with a few innovators at the beginning of the millennium has led to a veritable explosion of resources, such as blogs and podcasts over the past decade. ${ }^{3}$ These resources, which are promoted primarily via social media, have shifted the way that knowledge is translated into practice. Recent studies have demonstrated that new media are being used for education with $97.7 \%$ of American residents spending at least one hour per week supplementing their traditional academic curricula with podcasts ${ }^{4}$ and $99.5 \%$ of Canadian residents using free online resources for their general EM education. ${ }^{5}$ Tellingly, residents value entertainment and used wikis, podcasts, and screencasts significantly more than their program directors. ${ }^{5}$

The impact of social media and these online resources is demonstrated by their followership. CJEM-online.ca (CFEM's primary website until 2015) received an average of 43,000 page views/month in 2014. BoringEM.org, a blog founded by an EM resident (Thoma), receives approximately 35,000 page views/month, $60 \%$ of which come from outside of Canada. Dr. Ken Mine (the Skeptic's Guide to Emergency Medicine, theSGEM.com) and Dr. Anton Helman (EM Cases, emergencymedicinecases. com) have had similar success, regularly releasing podcasts that are downloaded between 5,000 and 10,000 times each. Some may argue that these resources do not possess the scholarly rigour to merit their notoriety, but they have grown to the point where they can no longer be ignored by the scholarly establishment. We believe that they are tapping into a niche that has been unfilled by journals by making it easier to consume and debate the literature. This trend toward convenience is likely attractive to busy clinicians trying to keep current with a constantly growing body of literature.

We see social media and online resources as a complement to the static content of traditional medical journals. This growing synergy has been demonstrated by journals that have developed engaging online strategies. For example, The Fournal of the American College of Radiology recently used Twitter "tweet chats" to increase online article views by $>30 \%$ and Web page views by $>25 \%{ }^{6}$ The Annals of Emergency Medicine and the EM blog, ALiEM.com, have organized online journal clubs that engage a diverse international population. A recent event had 1,401 readers and 313,229 Twitter audience impressions. ${ }^{7}$

With the rise of social media and online resources, academic journals are increasingly taking an active role in the translation of the research that they publish and have had varying levels of success. ${ }^{6-15}$ We believe that CFEM will benefit by embracing these evolving media and resources to become a leader in reader engagement.

From the *Emergency Medicine, University of Saskatchewan, Saskatoon, SK; †Department of Emergency Medicine, McGill University, Montreal, QC; $¥$ Canadian Association of Emergency Physicians, Ottawa, ON; and §Division of Emergency Medicine, Department of Medicine, McMaster University, Hamilton, ON.

Correspondence to: Dr. Brent Thoma, Emergency Medicine Residency Training Program, Room 2686, Royal University Hospital, 103 Hospital Drive, Saskatoon, SK S7N 0W8; Email: brent.thoma@usask.ca 


\section{THE NEW CFEM}

The road to a new CFEM began at the 2014 annual meeting of the CFEM editorial board. Aware of the shifting medical journal landscape, the board began considering how to modernize CFEM for the digital future. In late 2014, we were commissioned to prepare a report that outlined the online practices of other EM journals and made recommendations that would allow C7EM to harness the Internet to better reach, teach, and engage with CFEM readers, authors, and researchers.

Our analysis of major journals found that many had already devoted substantial resources to these goals. For example, their editorial boards contain social media editors, they have teams devoted to discussing and sharing articles on social media, and they have formalized relationships with blogs and podcasts. Other more experimental strategies included the use of written posts, podcasts, vodcasts, live video interviews, and peer-reviewed digests of social-media-based discussions and conference proceedings. ${ }^{7,9,11,15,16}$

$C F E M$ is now at the beginning of the transformation envisioned in our report. Beginning with the January 2015 issue, CFEM is an online-only journal with a new publisher, Cambridge University Press. This partnership increases the number of institutions with access to $C F E M$ and incorporates new capabilities to disseminate articles within weeks of acceptance. Led by the new CFEM Social Media Editorial Committee composed of medical students, residents, and emergency physicians fluent with online technology, CFEM will begin trialing online engagement strategies adopted from the best practices of other journals and developed by our team, specifically for the CFEM audience.

Following the publication of each issue, we will work with the authors of selected studies to assist in the dissemination and translation of their findings. Specific strategies will evolve over time, but we strongly believe that, beyond simply publishing knowledge, CFEM has a key role to play in ensuring that the information within its pages is integrated broadly into practice for the benefit of our patients. Our previous experience $e^{7,9,17}$ suggests that it is possible to engage physicians online, regardless of their pre-existing familiarity with online resources. The best ways to do this will be examined frequently as we adopt best practices and experiment with new ways to promote the research and ideas of Canadian physicians to an international audience.

\section{Measuring readership and engagement}

The transition to digital dissemination permits access to a treasure trove of new metrics to track article impact. Digital tools incorporated into the new CFEM website will track cumulative and absolute full-text article views (by year), article citations, and novel "altmetrics" (i.e., alternative metrics or article level metrics). Recent studies of altmetrics ${ }^{18}$ show that the impact of a journal (as measured by the journal impact factor and related metrics ${ }^{19}$ ) correlates with its online presence. ${ }^{20}$ Similarly, future citations for individual articles can be predicted based on the number of mentions that they receive on social media websites, such as Twitter. ${ }^{20,21}$

The Altmetric score will be posted for each CFEM article to allow users to track the relative impact of articles based on the quality and quantity of attention that they receive online. ${ }^{22}$ This score is calculated by amalgamating mentions of each article by news outlets, blogs, podcasts, tweets, Facebook, Mendeley, CiteULike, and other online platforms using a proprietary algorithm. ${ }^{23}$ The Altmetric score is increasingly being used by medical journals to track the relative impact of their articles. ${ }^{24}$ In addition, by clicking on the Altmetric score logo associated with each article, readers will be able to connect to valuable post-publication discussion.

The availability, responsiveness, and correlation with traditional measures of journal impact ${ }^{25}$ make altmetrics an attractive measure of success for CFEM's online engagement strategy. The editorial board, social media editors, and Social Media Editorial Committee will be watching their development closely to determine which metrics should be tracked and to set ambitious goals for enhancing the dissemination of CFEM content.

\section{Maintaining standards and quality}

While online resources have become quite popular, ubiquity does not necessitate quality. Although disruptive technologies have enabled a vast democratization of information, allowing the many to publish rather than just the few, this has also lead to high variability in the quality of disseminated materials. The expansion of FOAM is an example of one movement enabled by this change in technology.

The dark side of disruptive publishing via resources, such as FOAM blogs and podcasts, however, is that it is easy to self-publish without the benefit of traditional quality safeguards, such as editorial oversight and peer review. ${ }^{26}$ 
While traditional quality-assurance processes are used by some blogs, ${ }^{27}$ they are not practiced universally.

Additionally, the proliferation of online resources ${ }^{3}$ makes it challenging to identify the highest quality posts and sites. Unfortunately, critical appraisal guides ${ }^{28}$ and quality assessment tools ${ }^{29-33}$ for these resources have not yet been developed. This is an area of active research and educational scholarship for members of the inaugural CFEM Social Media Editorial Committee, and we will use our findings to ensure that CFEM collaborates with resources that have appropriate qualityassurance procedures and a track record of excellence.

Recognizing this, we encourage the CFEM readership to be vigilant and to identify misleading or erroneous content online. Most online resources are designed for social engagement, and post-publication comments are considered by many to be the primary check and balance of the online education ecosystem. ${ }^{27}$ Contributing to the online dialogue is essential for both the development of an engaged online community and to build upon the insights of others.

\section{CONCLUSION}

The inaugural Social Media Editorial Committee has proposed strategies that will transform CFEM into an engaging, digitally savvy journal with a ubiquitous online presence. We look forward to elucidating best practices that will capitalize on the opportunities offered by the journal's new online format and the explosive growth of online educational resources. Ultimately, we endeavour to make CFEM not only a journal that does more than merely publish research, but also a journal that engages front-line emergency practitioners in the translation of knowledge.

Keywords: Social Media, Altmetrics, Knowledge translation

Competing interests: None declared.

\section{REFERENCES}

1. Rogers EM. Diffusion of innovations, 4th edition. Simon and Schuster; 2010. Available at: http://books.google.com/ books?hl=en\&lr=\&id=v1ii4QsB7jIC\&pgis=1 (accessed January 15, 2015).

2. Nickson CP, Cadogan MD. Free Open Access Medical education (FOAM) for the emergency physician. Emerg Med Australas 2014;26(1):76-83. doi:10.1111/1742-6723.12191.

3. Cadogan M, Thoma B, Chan TM, et al. Free Open Access Meducation (FOAM): the rise of emergency medicine and critical care blogs and podcasts (2002-2013). Emerg Med 7: 2014;31(e1):e76-7, published online first. doi:10.1136/ emermed-2013-203502.

4. Mallin M, Schlein S, Doctor S, et al. A survey of the current utilization of asynchronous education among emergency medicine residents in the United States. Acad Med 2014;89(4):598-601. doi:10.1097/ACM.0000000000000170.

5. Purdy E, Thoma B, Bednarczyk J, et al. The use of free online educational resources by Canadian emergency medicine residents and program directors. CFEM 2015;17(2):101-6.

6. Hawkins CM, Hillman BJ, Carlos RC, et al. The impact of social media on readership of a peer-reviewed medical journal. $7 \mathrm{Am}$ Coll Radiol 2014;11(11):1038-43. doi:10.1016/j.jacr.2014.07.029.

7. Thoma B, Rolston D, Lin M. Global Emergency Medicine Journal Club: social media responses to the March 2014 Annals of Emergency Medicine journal club on targeted temperature management. Ann Emerg Med 2014;64(2): 207-212. doi:10.1016/j.annemergmed.2014.06.003.

8. Radecki RP, Rezaie SR, Lin M. Global Emergency Medicine Journal Club: social media responses to the November 2013 Annals of Emergency Medicine journal club. Ann Emerg Med 2014;63(4):490-4. doi:10.1016/j.annemergmed.2014.01.033.

9. Chan TM, Rosenberg H, Lin M. Global Emergency Medicine Journal Club: social media responses to the January 2014 online emergency medicine journal club on subarachnoid hemorrhage. Ann Emerg Med 2014;64(1): 88-94. doi:10.1016/j.annemergmed.2014.05.015.

10. Scott KR, Hsu CH, Johnson NJ, et al. Integration of social media in emergency medicine residency curriculum. Ann Emerg Med 2014;64(4):396-404. doi:10.1016/j.annemergmed.2014. 05.030.

11. Peer reviewed lectures. Acad Emerg Med. Available at: http:// onlinelibrary.wiley.com/journal/10.1111/(ISSN)1553-2712/ homepage/perls.htm (accessed December 16, 2015).

12. Fox CS, Bonaca MP, Ryan JJ, et al. A randomized trial of social media from circulation. Circulation 2015;131(1):28-33. doi:10.1161/CIRCULATIONAHA.114.013509.

13. Newman DH, Shreves AE. Annals audio and podcasting. Ann Emerg Med. Available at: http://www.annemergmed.com/ content/podcast (accessed December 16, 2014).

14. Brown AFT. The road less traveled: an editor's journey. Emerg Med Australas 2014;26(1):1-2. doi:10.1111/1742-6723.12185.

15. Brown AFT. Don't let herpes melt your brain! Ann Emerg Med 2014;64(6):589-90. doi:10.1016/j.annemergmed.2014.10.027.

16. Thoma B, Joshi N, Trueger NS, et al. Five strategies to effectively use online resources in emergency medicine. Ann Emerg Med 2014;64(4):392-5. doi:10.1016/j.annemergmed.2014. 05.029 .

17. Chan TM, Thoma B, Lin M, editors. Medical education in cases: volume 1. First edit. San Francisco, California: Academic Life in Emergency Medicine; 2014. Available at: https://itunes.apple.com/ca/book/medical-education-in-cases/ id929609481? mt=13 (accessed January 15, 2015).

18. Priem J, Groth P, Taraborelli D. The altmetrics collection. PLOS One 2012;7(11):e48753. doi:10.1371/journal.pone.0048753.

19. Thomson-Reuters Corporation. 2013 Journal Citation Reports ${ }^{\circledR}$ Science Edition; 2012.

20. Evans P, Krauthammer M. Exploring the use of social media to measure journal article impact. AMLA Annu Symp Proc Arch 
2011;2011:374-81. Available at: http://www.pubmedcentral. nih.gov/articlerender.fcgi? artid $=3243242 \&$ tool=pmcentrez $\&$ rendertype $=$ abstract $($ accessed January 16, 2015).

21. Eysenbach G. Can tweets predict citations? Metrics of social impact based on Twitter and correlation with traditional metrics of scientific impact background. 7 Med Internet Res 2011;13(4):e123.

22. Altmetric.com. What does altmetric do? Available at: http://www. altmetric.com/whatwedo.php (accessed January 16, 2015).

23. Altmetric.com. How is the Altmetric score calculated? Available at: http://support.altmetric.com/knowledgebase/ articles/83337-how-is-the-altmetric-score-calculated (accessed January 16, 2015).

24. Kwok R. Research Impact: Altmetrics make their mark. Nature 500:491-3. doi:10.1038/nj7463-491a.

25. Thoma B, Sanders J, Paterson Q, et al. The Social Media Index: curating emergency medicine blogs and podcasts. In Canadian Association of Emergency Physicians Annual Conference. Ottawa; 2014.

26. Brabazon T. The Google effect: googling, blogging, wikis and the flattening of expertise. Libri 2006;56(3):157-67. doi:10.1515/LIBR.2006.157.

27. Thoma B, Chan TM, Desouza N, et al. Implementing peer review at an emergency medicine blog: bridging the gap between educators and clinical experts. C7EM 2015;17(2): 188-91. doi: $10.2310 / 8000.2014 .141393$.
28. Guyatt G, Rennie D, Meade MO, et al. Users' guides to the medical literature: a manual for evidence-based clinical practice, 2nd edition. New York: McGraw-Hill Education; 2008.

29. Charnock D, Shepperd S, Needham G, et al. DISCERN: an instrument for judging the quality of written consumer health information on treatment choices. 7 Epidemiol Community Health 1999;53(2):105-11; Available at: http://www.pubmedcentral.nih.gov/articlerender.fcgi? artid $=1756830 \&$ tool $=$ pmcentrez\&rendertype $=$ abstract (accessed January 15, 2015).

30. Boyer C, Selby M, Scherrer J-R, et al. The Health On the Net Code of Conduct for medical and health websites. Comput Biol Med 1998;28(5):603-10. doi:10.1016/S0010-4825(98) 00037-7.

31. Moher D, Liberati A, Tetzlaff J, et al. The PRISMA Statement for Reporting Systematic Reviews and MetaAnalyses of Studies That Evaluate Health Care Interventions: Explanation and Elaboration. Ann Intern Med 2009;151:264-9.

32. Higgins JP, Green S. Cochrane Handbook for Systematic Reviews of Interventions. Chicester: Wiley; 2008.

33. O'Brien BC, Harris IB, Beckman TJ, et al. Standards for reporting qualitative research: a synthesis of recommendations. Acad Med 2014;89(9):1245-51. doi:10.1097/ACM.00000000000 $\underline{00388 .}$. 